\title{
Individual differences in perceived social desirability of openness to experience: A new framework for social desirability responding in personality research ${ }^{\text {i⿱ }}$
}

\author{
Annique Smeding ${ }^{\mathrm{a}, *}$, Benoît Dompnier ${ }^{\mathrm{b}}$, Céline Darnon ${ }^{\mathrm{c}}$ \\ a Univ. Savoie Mont Blanc, France \\ ${ }^{\mathrm{b}}$ Univ. of Lausanne, Switzerland \\ c Univ. Clermont Auvergne, France
}

\section{A R T I C L E I N F O}

\section{Article history:}

Received 27 September 2016

Received in revised form 8 March 2017

Accepted 11 March 2017

Available online 19 March 2017

\section{Keywords:}

Openness to experience

Individual differences

Perceived social desirability

Social value

\begin{abstract}
A B S T R A C T
The extent to which response distortion - such as social desirability responding (SDR) - is present in self-report measures is an issue of concern and debate in personality research, as it may seriously impact such measures' psychometric indices. The present research aimed at using the social value framework to shed new light on SDR in self-report personality tests. Two studies tested the moderating role of individual differences in perceived social desirability of the Openness to Experience dimension for test-retest reliability and predictive validity of a typical Openness measure. Results support the hypothesized moderating role of perceived social desirability for improving test-retest reliability, providing the testing condition guarantees full anonymity (Study 1 ), and for predictive validity (Study 2). Findings are discussed with regards to SDR in personality research and the social value framework.
\end{abstract}

(c) 2017 Elsevier Ltd. All rights reserved.
The extent to which response distortion - such as social desirability responding (SDR) - is present in self-report personality tests is an issue of concern and debate, as it may seriously impact such measures' psychometric indices, including reliability and predictive validity, (e.g., Burns \& Christiansen, 2011; Ganster, Hennessey, \& Luthans, 1983; Paunonen \& LeBel, 2012; Rosse, Stecher, Miller, \& Levin, 1998). Here we aimed at using a new approach based on perceived social value of personality dimensions to shed new light on SDR in self-report personality tests. We focused on individual differences in perceived social desirability of the Openness to Experience dimension and on their crucial moderating role when examining test-retest reliability and predictive validity of an Openness measure (extracted from the Big Five Inventory; John, Donahue, \& Kentle, 1991).

\section{Social desirability responding in personality research}

The definition of SDR is still debated in the personality literature (see Paulhus, 2002; Uziel, 2010). As an illustration, SDR has recently been

it The authors sincerely thank J.C. Quinton for his help in generating and updating the R code for the Supplementary Material as well as Emmanuelle Neuville and Claire Migne for their help in data collection.

* Corresponding author at: Univ. Savoie Mont Blanc, LIP/PC2S, BP 1104, 73011 Chambéry cedex, France.

E-mail address: Annique.Smeding@univ-smb.fr (A. Smeding). conceived of as both a response distortion and a tendency of the test respondent "to select as self-descriptive the response options for items that are more desirable than warranted by his or her corresponding traits or behaviors" (Paunonen \& LeBel, 2012, pp. 158-159). This tendency can be conscious and deliberate or unconscious, and can be conceived as an individual difference variable (Paunonen \& LeBel, 2012). SDR can thus be conceived both as a bias and an individual difference variable. For theoretical and methodological reasons it is crucial, in the present perspective, to operate a clear distinction between these two elements (see also Paulhus, 1991, who differentiates - in another framework - contextual-based social desirability response sets from social desirability response styles, an individual differences variable).

As an individual differences variable, SDR can be conceptualized as being normally distributed in a given population (Paunonen \& LeBel, 2012) and as a latent psychological construct that cannot directly be assessed (Bollen, 2002). When SDR is conceived of as a bias, it should be possible to rely on empirical indicators to approximate it, given the systematicity of some of its features (e.g., an average positive bias in the case of desirable traits if situational demands implicitly or explicitly require positive self-portrayals). Presumably, these two conceptions of SDR may be partially related, as individual differences on the SDR-latent variable may manifest in individual differences in SDR-bias (i.e., individuals at the right tail of the distribution will, on average, bias their responses more). Ultimately however, it is SDR as a bias that ought to capture attention if the emphasis is on psychometric indices, because 
it can affect their soundness, including reliability and predictive validity (Burns \& Christiansen, 2011; Ganster et al., 1983; Paunonen \& LeBel, 2012; Rosse et al., 1998). Henceforth, we will focus on SDR as a (positive) bias only and will refer to it by the generic term SDR.

\section{Assessing social desirability responding within the social value approach}

Originally, SDR has been assessed with scales, like the MarloweCrowne Social Desirability Scale (Crowne \& Marlowe, 1960), which measure individuals' tendency to over report infrequent socially desirable behaviors and underreport frequent undesirable behaviors. Scores on social desirability scales can subsequently be related to individuals' responses on other measures, including self-report personality tests. Another way to estimate SDR in personality research is to compare mean scores for a given dimension obtained under honest and self-presentation (e.g., fake good) instructions (e.g., Holden \& Evoy, 2005; McFarland \& Ryan, 2000; Viswesvaran \& Ones, 1999). Findings relying on this procedure usually show that mean scores for desirable traits are higher under self-presentation than under honest instructions, suggesting that participants can bias their responses if desired.

Accordingly, most research on SDR in the personality literature has focused on these mean differences - including the inflation of scores between honest and self-presentation instructions (McFarland \& Ryan, 2000) - while overlooking individual differences in responses under the latter type of instructions. This is unfortunate as findings in the achievement motivation literature suggest that individual differences in responses under self-presentation instructions contribute to clarify the meaning and to improve predictive validity of responses on the same measure obtained under honest instructions (Dompnier, Darnon, \& Butera, 2009, 2013; Smeding et al., 2015). Specifically, this line of research - hereafter labeled social value approach - suggests that individuals' responses under self-presentation instructions (typically, asking students to respond to questionnaire items to make themselves likeable and popular with their teachers; Dompnier et al., 2009) reflect individual differences in perceived social desirability of the construct.

Within the social value framework it seems possible to integrate the individual differences and mean differences approaches, by measuring individual differences in self-report responses under self-presentation instructions. According to this perspective, the impact of a given measure - assessed under honest instructions - on the outcome depends on conditional values of perceived social desirability of the measured construct - assessed under self-presentation instructions - because they change the very meaning of individuals' answers to the measurement tool (cf. Dompnier et al., 2013). Specifically, at low levels of perceived social desirability, individuals' responses under honest instructions reflect to a high extent self-perceptions on the construct because they do not have the knowledge (or have it to a lesser extent) that would enable them to modify their responses to adapt to what is socially valued in a given context. Instead, at high levels of perceived social desirability, individuals' responses under honest instructions do not necessarily reflect self-perceptions on the construct because they have knowledge of what is socially desirable and thus may adapt their answers accordingly.

Our objective here is to use the social value framework to test this moderation effect on another construct widely used in personality research: The Big Five, and, specifically, the Openness to Experience dimension of the Big Five Inventory (BFI; John et al., 1991). Indeed, Openness may be considered as the most theoretically relevant dimension given its relation to overclaiming and self-presentation (e.g., Dunlop et al., In press). College students - which is our target population here - are particularly likely to present themselves as intellectuals and knowledgeable when they answer to a personality test in a university context.

\section{Research overview and hypotheses}

Our first objective was to test the general hypothesis that individual differences in perceived social desirability of Openness (obtained under self-presentation instructions) moderate levels of reliability and validity of its measure under honest instructions. Our second objective was to test the impact of testing condition as a determining factor in our model, as we assume construct validity to be maximal if testing condition does not encourage response modification for self-presentation purposes. A prototypical example of such a condition is one in which responses are given under explicit anonymity instructions. We investigated both hypotheses in two studies.

In Study 1 we investigated test-retest reliability of the Openness measure and to what extent individual differences in Openness' perceived social desirability (i.e., under self-presentation instructions) moderate the link between the same Openness measures spaced by a one-month time delay. In addition, we manipulated participants' motivation to fake their answers on the retest measure by placing them in an explicit anonymity condition or an explicit visibility condition. We expected test-retest reliability of the Openness measure to increase as Openness' perceived social desirability decreased, but only in the anonymity condition (it should be noted that, given the addition of several predictors, using the term "test-retest reliability" is unusual; however, as it is the most parsimonious term to convey our hypotheses, we maintain it in the manuscript).

In Study 2 we tested the same hypotheses as in Study 1, but focused on predictive validity of the Openness measure by using a valid behavioral, performance-based indicator as independent external criterion (i.e., a cultural knowledge test designed to be related to the intellectual and creative aspects of Openness; cf. Back, Schmukle, \& Egloff, 2009). Another modification was the manipulation of condition at the onset of the study. We expected predictive validity of the Openness measure to increase as a function of the decrease of participants' perception of this dimension's social desirability, especially in a condition that does not encourage response modification for self-presentation purposes. Thus we assumed perceived social desirability of Openness to negatively moderate the link between self-reported Openness and the performance measure of Openness in an anonymity condition, but not in a visibility condition.

\section{Study 1}

\subsection{Method}

\subsubsection{Participants and design}

Sixty undergraduate psychology students ( 6 male, 1 unreported) were recruited from the introductory psychology pool and participated in exchange for course credit. At the beginning of the fall semester (session 1 , test phase), they completed an anonymous mass survey, which included the relevant Openness measure. One month later (session 2, retest phase), they were invited for an unrelated laboratory study on Personality and completed the same Openness measure a second time, either in an anonymity (33 participants) or visibility condition (27 participants). Assignment to conditions was random (Table 1).

Table 1

Study 1 regression analysis predicting retest phase openness scores.

\begin{tabular}{llll}
\hline Predictors & $b$ & $S E$ & $t$ \\
\hline Condition (anonymity -1, visibility 1) & 0.02 & 0.06 & 0.28 \\
Openness (honest instructions) (OS) & 0.72 & 0.13 & 5.46 \\
Perceived social desirability of Openness (OD) & -0.01 & 0.09 & -0.87 \\
Condition * OS & -0.20 & 0.13 & -1.52 \\
Condition * OD & 0.19 & 0.09 & 2.15 \\
OS $*$ OD & -0.21 & 0.16 & -1.35 \\
Condition $*$ OS $*$ OD & 0.32 & 0.16 & 2.02 \\
\hline
\end{tabular}




\subsubsection{Materials and procedure}

4.1.2.1. Test phase (session 1). Participants completed the 10-item Openness measure of the BFI, French version (Plaisant, Courtois, Réveillère, Mendelsohn, \& John, 2010) during a large mass survey. At the beginning of the mass survey, participants were informed that their answers at this mass testing would be totally anonymous. All ratings were provided on 5 -point scales ( $1=$ strongly disagree; $5=$ strongly agree $)$. As in previous research (Dompnier et al., 2009), participants responded to the Openness measure twice: First under honest $(M=3.32, S D=$ $0.52, \alpha=0.60)$ and then under social desirability instructions $(M=$ $3.80, S D=0.81, \alpha=0.87$ ). Under honest instructions, participants were invited to respond honestly and to indicate their own level of agreement with each item. Under social desirability instructions, as in Dompnier et al. (2009), participants were asked to answer with a view of presenting themselves as if they possessed all the qualities to make themselves likeable and popular with their teachers $(r=$ $0.42, p<0.01)$.

4.1.2.2. Retest phase (session 2). Upon arrival, participants signed a consent form and were seated in individual cubicles. Anonymity versus visibility instructions are detailed as supplementary material. Participants subsequently filled out the same Openness measure as in session 1 under honest instructions only $(M=3.74, S D=0.58, \alpha=0.75)$, were thanked and fully debriefed.

\subsection{Results}

The regression model included all session 1 predictors, that is, condition (anonymity: -1 , visibility: 1 ), session 1 Openness scores under honest instructions, session 1 Openness scores under social desirability instructions, and interaction products among these variables (i.e., three two-way interactions, one three-way interaction). All predictors were mean-centered and unstandardized coefficients are reported. We regressed session 2 Openness scores on the seven predictors of the model (adjusted $R^{2}=0.52, F(7,52)=10.01, p<0.001$ ). Results showed a positive effect of session 1's Openness scores under honest instructions, $b=0.72, t(52)=5.46, p<0.001, \eta_{p}^{2}=0.36$, and an interaction effect between condition and Openness scores under social desirability instructions, $b=0.19, t(52)=2.15, p<0.04, \eta_{p}^{2}=0.08$. This effect was qualified by a significant three-way interaction effect between condition, Openness scores under honest instructions, and Openness scores under social desirability instructions, $b=0.32, t(52)=2.02, p<0.05$, $\eta_{p}^{2}=0.07$.

Analyses for the anonymity condition showed an effect of Openness scores under honest, $b=0.92, t(52)=6.95, p<0.001$, and social desirability instructions, $b=-0.27, t(52)=-2.39, p=0.02$. More importantly, the expected interaction effect between these two predictors was found, $b=-0.53, t(52)=-3.02, p<0.001$. As illustrated in Fig. 1 , this interaction indicated that as Openness' perceived social desirability decreased, the link between session 1 Openness scores under honest instructions and these scores obtained in session 2 increased. Accordingly, when testing this link at a low level (minus one standard deviation) of perceived social desirability, session 1 Openness scores were strongly related to session 2 scores, $b=1.35, t(52)=6.57, p<0.001$. When testing this link at a high level (plus one standard deviation), the magnitude of this positive link dropped drastically, $b=0.49$, $t(52)=2.68, p<0.02$. We conducted the same analyses for the visibility condition. Results showed an effect of Openness scores under honest instructions, but of lesser magnitude compared to the anonymity condition, $b=0.52, t(52)=2.27, p<0.03$. Also, the interaction effect between Openness scores under honest and social desirability instructions, which was significant in the anonymity condition, was non-significant here $(t=0.40)$.
Study 1/Anonymity Condition

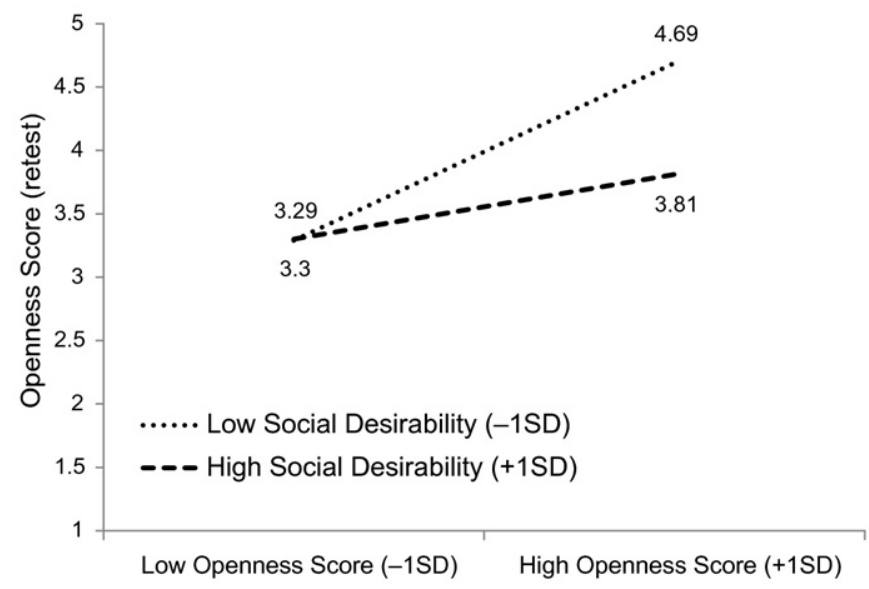

Study $1 /$ Visibility Condition

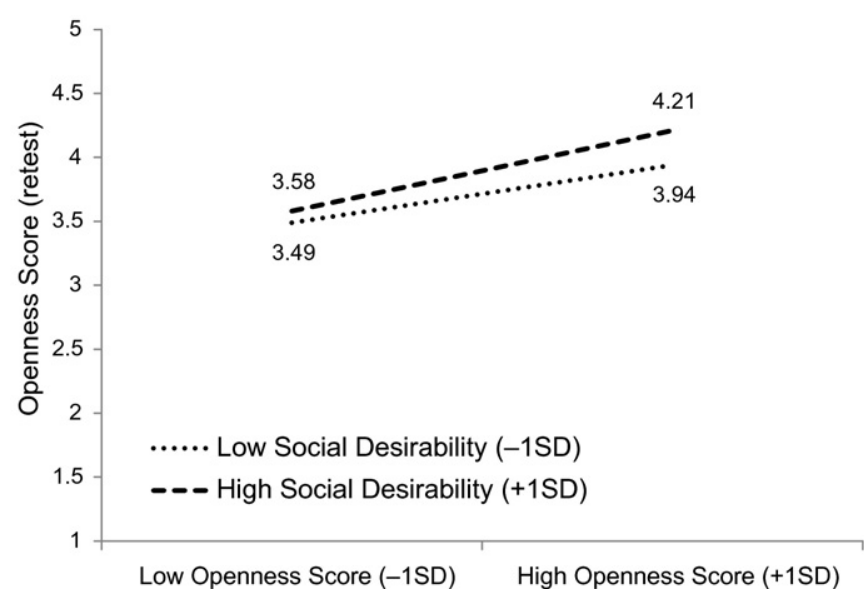

Fig. 1. Openness scores measured during the retest phase as a function of Openness (honest instructions), perceived social desirability of Openness, and condition (Study 1).

\subsection{Discussion}

Consistent with hypothesis, findings show that taking into account openness' perceived social desirability contributes at clarifying which individuals drive test-retest reliability of a commonly used self-report Openness to Experience measure. As expected, based on past research (Dompnier et al., 2009, 2013; Smeding et al., 2015), session 1 Openness scores were strongly related to session 2 Openness scores when individuals did not respond for social desirability reasons during session 1 and when full anonymity was guaranteed during session 2 . Study 2 aimed at extending Study 1 by investigating another aspect of construct validity, namely predictive validity. We tested the effects of perceived social desirability and testing condition on the link between self-reported Openness scores and a behavioral, performance-based Openness measure, with both measures being collected during the same session.

\section{Study 2}

\subsection{Method}

\subsubsection{Participants and design}

Participants were 74 psychology undergraduates ( 10 male; $M=21$, $S D=7.21$ ) who participated in exchange for course credit. One participant was removed from analyses because of an extreme value of Mahalanobis distance. Participants were randomly assigned to the 
Table 2

Study 2 regression analysis predicting cultural knowledge test scores.

\begin{tabular}{llll}
\hline Predictors & $b$ & $S E$ & $t$ \\
\hline Condition (anonymity -1, visibility 1) & 0.10 & 0.40 & 0.25 \\
Openness (honest instructions) (OS) & 2.20 & 0.74 & 2.96 \\
Perceived social desirability of Openness (OD) & -0.35 & 0.74 & -0.48 \\
Condition * OS & 0.63 & 0.74 & 0.84 \\
Condition * OD & -1.08 & 0.74 & -1.46 \\
OS $*$ OD & -2.48 & 1.34 & -1.85 \\
Condition $*$ OS $*$ OD & -0.44 & 1.34 & -0.33 \\
\hline
\end{tabular}

anonymity (37 participants) or visibility condition (36 participants) (Table 2).

\subsubsection{Materials and procedure}

Upon arrival, participants signed a consent form and were seated in individual cubicles. They first received either the anonymity or visibility condition instructions (same instructions as in Study 1), and subsequently completed the Openness measure of the BFI. As in Study 1, participants responded to this measure twice $(r=0.41 p<0.01)$ : First under honest instructions ( $M=3.51, S D=0.57, \alpha=0.72)$ and then under social desirability instructions $(M=4.12, S D=0.57, \alpha=0.81)$.

Participants were then invited to complete the cultural knowledge test adapted from Back et al. (2009). This test comprised 20 multiple choice and 5 open-ended questions. Sample items included "The Channel Tunnel is the longest undersea tunnel in the world with its: 20.5 kilometers/30.5 kilometers/50.5 kilometers/70.5 kilometers" and "What is Pope Francis's real name? Jorge Mario Bergoglio/Bernardino Rivadavia/Cristiano Fernandez/Josè Ignacio Alvarez". One point was allocated to each correct answer, resulting in a maximal score of $25(M=12.55, S D=3.32)$. Testing time was limited to $10 \mathrm{~min}$. After filling out some additional measures, which were not relevant for the present research, and demographic information (including gender and age), participants were thanked and thoroughly debriefed.

\subsection{Results}

As in Study 1, we regressed cultural knowledge test scores on the same seven mean centered predictors (adjusted $R^{2}=0.13, F(7$, $65)=2.59, p<0.03$ ). Results revealed a positive effect of Openness scores under honest instructions, $b=2.20, t(65)=2.96, p<0.01$, $\eta_{p}^{2}=0.12$, and an interaction effect between Openness scores under honest and social desirability instructions that approached conventional levels of significance, $b=-2.48, t(65)=-1.85, p=0.07, \eta_{p}^{2}=0.05$. No other effect was significant (all $p s>0.15$ ). As our general hypothesis pertained to the moderating role of individual differences in Openness's perceived social desirability, with the self-reported and performancebased Openness measures link expected to increase as Openness' perceived social desirability decreased, we tested this link at low (minus one standard deviation) and high (plus one standard deviation) levels of perceived social desirability. As expected, self-reported Openness was strongly and positively related to behavioral Openness when Openness's perceived social desirability was low, $b=3.61, t(65)=$ $3.14, p<0.01$, but this link dropped to non-significance when perceived social desirability was high, $b=0.79, t(65)=0.82, n s$. This pattern is illustrated in Fig. 2.

\subsection{Discussion}

Results of Study 2 indicate that the link between self-reported Openness and a performance measure of Openness varies at conditional values of Openness' perceived social desirability. As in Study 1, this suggests that the link between self-reported and behavioral, performancebased Openness measures may be driven by those individuals who do not (or do so to a lesser extent) perceive Openness as being socially desirable. In Study 2 however, testing condition (anonymity versus

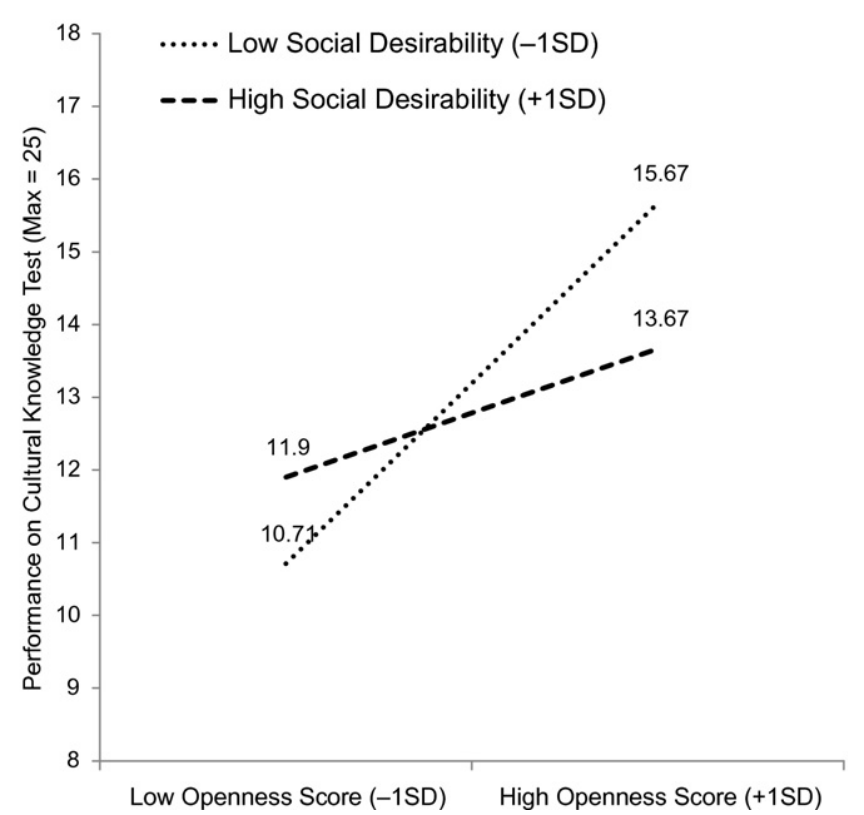

Fig. 2. Performance on the cultural knowledge test as a function of Openness (honest instructions) and perceived social desirability of Openness (Study 2).

visibility) did not have any impact. This finding differs from Study 1 , and will be discussed in the General Discussion.

\section{General discussion}

In the present research, our general objective was to use the social value framework in the personality domain and test the moderating role of individual differences in perceived social desirability of the Openness to Experience dimension on its construct validity. In two studies, we tested this moderation for test-retest reliability (Study 1) and predictive validity (Study 2). A second and related aim was to examine the importance of testing condition (explicit anonymity versus visibility instructions). In Study 1, where testing instructions were given just before completion of the self-report retest measure, moderation of Openness' perceived social desirability was indeed only observed in the anonymity condition, not in the visibility condition. Study 2 confirmed some of these findings: While results suggest that the link between self-reported Openness and a performance measure of Openness varies at conditional values of Openness' perceived social desirability, testing condition did not alter this effect. These observed differences related to testing condition may be best explained by methodological variations, as timing of presentation of the anonymity/ visibility instructions differed in the two studies: Just before completion of the self-report measure in Study 1 and at the onset of the study in Study 2. Consequently, testing condition was not specific and restricted to completion of the criterion in Study 2. In addition, the very nature of the two measures - self-reports versus behavioral, performance-based criteria - differed, with the latter quite impossible to positively bias, contrary to the former. Another explanation may be related to the fact that in some contexts, visibility per se is not sufficient to systematically encourage individuals to fake their self-reported answers. Other social factors, such as evaluative pressure or social presence known to impact behavioral outcomes (e.g., Beilock, 2008; Triplett, 1898), may additionally be required to generate sufficient incentives in laboratory settings to systematically encourage faking. Future research should investigate this issue in order to identify those situational constraints that maximize individuals' motivation to fake their answers during personality testing, and beyond.

Regarding SDR in personality research and the social value literature, the present findings contribute to both areas in several ways. First, they 
support the relevance of taking into account individual differences in perceived social desirability of the Openness dimension, with both test-retest reliability (in the anonymity condition) and predictive validity being improved at lower levels of perceived social desirability. This suggests that at low - but not at high - levels of perceived social desirability of Openness, individuals do not have the knowledge (or have it to a lesser extent) to respond in a socially desirable fashion, resulting in more accurate answers (regarding available self-perceptions) and therefore an increase in reliability and validity. The present findings therefore provide evidence that the meaning of individuals' self-reports on the Openness dimension may differ as a function of their level of perceived social desirability of this same construct. Importantly, these findings currently apply to the Openness dimension and a specific population only (undergraduate psychology students, predominantly female). To test for generalizability, future research should test hypotheses for all typical Big Five dimensions (i.e., Agreeableness, Conscientiousness, Extraversion, and Neuroticism), preferably among samples from various relevant populations.

Second, findings partly support the idea, developed by others (Paulhus, 1991) that contextual factors in personality research - like the anonymity versus visibility conditions implemented in the present work - matter for construct validity. Results from Study 1 empirically support the importance of testing conditions in the personality domain, an issue that can be put in perspective with the historical development of personality tests (Spencer, 1938). Indeed, given that early personality test development relied on the field of intelligence testing, that is, on measures for which scores cannot be improved to generate a positive image if the underlying knowledge is lacking, the issue of anonymous testing conditions has not been a concern at the onset. Since theses early developments, it has been assumed that anonymity reduces SDR, with research indicating that individuals' reports of undesirable characteristics are higher in anonymity conditions than in visibility conditions (Booth-Kewley, Edwards, \& Rosenfeld, 1992; Lautenschlager \& Flaherty, 1990; Paulhus, 1984; but see Holden, Magruder, Stein, Sitarenios, \& Sheldon, 1999). In a complementary way, our focus on the impact of contextual factors on measures' psychometric indices provides new evidence supporting the importance of anonymous testing conditions in the case of self-report (personality) measures.

Third, although we are not the first to assume the methodological relevance of the moderation hypothesis in personality and organizational research (Ganster et al., 1983; Holden, 2007; Moorman \& Podsakoff, 1992), we are the first to integrate this approach in a theoretical framework that has proven very relevant in other areas (i.e., motivation research; Dompnier et al., 2009, 2013; Smeding et al., 2015). It suggests the importance of individual differences in perceived social desirability of the construct (i.e., scores on a self-report Openness to Experience measure collected under self-presentation instructions) to test for moderation, because these individual differences change the meaning one gives to individuals' responses on the same measure collected under standard (honest) instructions. This qualitative change as a function of individual differences is not investigated when the focus is on mean score difference between honest and self-presentation conditions (McFarland \& Ryan, 2000). We therefore suggest that the two approaches investigate complementary research questions. The mean score difference approach allows determining whether participants can bias their responses if desired/instructed to do so, whether there is a mean shift (in what direction), and whether rank order changed. It does not help qualifying the meaning of responses under honest instructions, which is what the combined social value and moderation approach allows.

In the end, what we particularly want to emphasize is the potential added value for personality research of the social value framework, its related methodology by taking into account individual differences in perceived social desirability and, in the case of Study 1, the importance of testing conditions in explaining response variability. Given that this added value can be achieved at rather reduced costs, the present methodology may open new perspectives for professionals aiming at improving reliability and validity in various applied domains.

\section{Appendix A. Supplementary data}

Supplementary data to this article can be found online at http://dx. doi.org/10.1016/j.paid.2017.03.028.

\section{References}

Back, M. D., Schmukle, S. C., \& Egloff, B. (2009). Predicting actual behavior from the explicit and implicit self-concept of personality. Journal of Personality and Social Psychology, 97, 533-548. http://dx.doi.org/10.1037/a0016229.

Beilock, S. L. (2008). Math performance in stressful situations. Current Directions in Psychological Science, 17, 339-343. http://dx.doi.org/10.1111/j.1467-8721.2008. 00602.x

Bollen, K. A. (2002). Latent variables in psychology and the social sciences. Annual Review of Psychology, 53, 605-634. http://dx.doi.org/10.1146/annurev.psych.53.100901. 135239.

Booth-Kewley, S., Edwards, J. E., \& Rosenfeld, P. (1992). Impression management, social desirability, and computer administration of attitude questionnaires: Does the computer make a difference? Journal of Applied Psychology, 77, 562-566. http://dx.doi. org/10.1037/0021-9010.77.4.562.

Burns, G. N., \& Christiansen, N. D. (2011). Methods of measuring faking behavior. Human Performance, 24, 358-372. http://dx.doi.org/10.1080/08959285.2011.597473.

Crowne, D. P., \& Marlowe, D. A. (1960). A new scale of social desirability independent of psychopathology. Journal of Consulting Psychology, 4, 349-354. http://dx.doi.org/10. 1037/h0047358.

Dompnier, B., Darnon, C., \& Butera, F. (2009). Faking the desire to learn: A clarification of the link between mastery goals and academic achievement. Psychological Science, 20, 939-943. http://dx.doi.org/10.1111/j.1467-9280.2009.02384.x.

Dompnier, B., Darnon, C., \& Butera, F. (2013). When performance-approach goals predict academic achievement and when they do not: A social value approach. British Journal of Social Psychology, 52, 587-596. http://dx.doi.org/10.1111/bjso.12025.

Dunlop, P. D., Bourdage, J. S., de Vries, R. E., Hilbig, B. E., Zettler, I., \& Ludeke, S. G. Openness to (reporting) experiences that one never had: Overclaiming as an outcome of the knowledge accumulated through a proclivity for cognitive and aesthetic exploration. Journal of Personality and Social Psychology. Advance online publication. doi: 10. 1037/pspp0000110 (In press)

Ganster, D. C., Hennessey, H. W., \& Luthans, F. (1983). Social desirability response effects: Three alternative models. Academy of Management Journal, 26, 321-331. http://dx. doi.org/10.2307/255979.

Holden, R. R. (2007). Socially desirable responding does moderate personality scale validity both in experimental and in nonexperimental contexts. Canadian Journal of Behavioural Science/Revue Canadienne des Sciences du Comportement, 39, 184-201. http://dx.doi.org/10.1037/cjbs2007015.

Holden, R. R., \& Evoy, R. A. (2005). Personality inventory faking: A four-dimensional simulation of dissimulation. Personality and Individual Differences, 39, 1307-1318. http:// dx.doi.org/10.1016/j.paid.2005.06.007.

Holden, R. R., Magruder, C. D., Stein, S. J., Sitarenios, G., \& Sheldon, S. (1999). The effects of anonymity on the Holden psychological screening inventory. Personality and Individual Differences, 27, 737-742. http://dx.doi.org/10.1016/S01918869(98)00274-8

John, O. P., Donahue, E. M., \& Kentle, R. L. (1991). The big five inventory-Versions 4a and 54. Berkeley: University of California, Berkeley, Institute of Personality and Social Research.

Lautenschlager, G. J., \& Flaherty, F. L. (1990). Computer administration of questions: More desirable or more social desirability? Journal of Applied Psychology, 75, 310-314.

McFarland, L. A. \& Ryan, A. M. (2000). Variance in faking across noncognitive measures. Journal of Applied Psychology, 85, 812. http://dx.doi.org/10.1037/0021-9010.85.5.812.

Moorman, R. H., \& Podsakoff, P. M. (1992). A meta-analytic review and empirical test of the potential confounding effects of social desirability response sets in organizational behaviour research. Journal of Occupational and Organizational Psychology, 65, 131-149. http://dx.doi.org/10.1111/j.2044-8325.1992.tb00490.x.

Paulhus, D. L. (1984). Two-component models of socially desirable responding. Journal of Personality and Social Psychology, 46, 598-609. http://dx.doi.org/10.1037/0022-3514. 46.3.598.

Paulhus, D. L. (1991). Measurement and control of response bias. In J. P. Robinson, P. R. Shaver, \& L. S. Wrightsman (Eds.), Measures of personality and social psychological attitudes (pp. 17-60). San Diego: Academic Press.

Paulhus, D. L. (2002). Social desirable responding: The evolution of a construct. In H. I. Braun, D. N. Jackson, \& D. E. Wiley (Eds.), The role of constructs in psychological and educational measurement (pp. 49-69). Mahwah, NJ: Erlbaum.

Paunonen, S. V., \& LeBel, E. P. (2012). Socially desirable responding and its elusive effects on the validity of personality assessments. Journal of Personality and Social Psychology, 103, 158-175. http://dx.doi.org/10.1037/a0028165.

Plaisant, O., Courtois, R., Réveillère, C., Mendelsohn, G. A. \& John, O. P. (2010). Validation par analyse factorielle du Big Five Inventory français (BFI-Fr). Analyse convergente avec le NEO-PI-R [French validation via factorial analysis of the French version of the Big Five Inventory (BFI-Fr). Convergent validity with the NEO-PI-R]. Annales Médico-Psychologiques, 168, 97-106. http://dx.doi.org/10.1016/j.amp.2009.09.003.

Rosse, J. G., Stecher, M. D., Miller, J. L., \& Levin, R. A. (1998). The impact of response distortion on preemployment personality testing and hiring decisions. Journal of Applied Psychology, 83, 634-644. http://dx.doi.org/10.1037/0021-9010.83.4.634. 
Smeding, A., Dompnier, B., Meier, E., Darnon, C., Baumberger, B., \& Butera, F. (2015). The motivation to learn as a self-presentation tool among Swiss high school students: The moderating role of mastery goals' perceived social value on learning. Learning and Individual Differences, 43, 204-210. http://dx.doi.org/10.1016/j.lindif.2015.08.036.

Spencer, D. (1938). The frankness of subjects on personality measures. Journal of Educational Psychology, 29, 26-35. http://dx.doi.org/10.1037/h0061518.

Triplett, N. (1898). The dynamogenic factors in pacemaking and competition. American Journal of Psychology, 9, 507-533.
Uziel, L. (2010). Rethinking social desirability scales from impression management to interpersonally oriented self-control. Perspectives on Psychological Science, 5, 243-262. http://dx.doi.org/10.1117/1745691610369465.

Viswesvaran, C., \& Ones, D. S. (1999). Meta-analyses of fakability estimates: Implications for personality measurement. Educational and Psychological Measurement, 59, 197-210 (doi: 00131649921969802). 